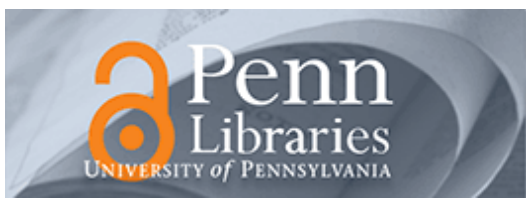

University of Pennsylvania ScholarlyCommons

Wharton Pension Research Council Working

Papers

Wharton Pension Research Council

9-1-2005

\title{
Regret, Portfolio Choice, and Guarantees in Defined Contribution Schemes
}

Alexander Alexander Muermann

The Wharton School, University of Pennsylvania, alexander.muermann@wu.ac.at

Olivia S. Mitchell

The Wharton School, University of Pennsylvania, mitchelo@wharton.upenn.edu

Jacqueline M. Volkman

The Wharton School, University of Pennsylvania

Follow this and additional works at: https://repository.upenn.edu/prc_papers

Part of the Economics Commons

Alexander Muermann, Alexander; Mitchell, Olivia S.; and Volkman, Jacqueline M., "Regret, Portfolio Choice, and Guarantees in Defined Contribution Schemes" (2005). Wharton Pension Research Council Working Papers. 390.

https://repository.upenn.edu/prc_papers/390

This paper is posted at ScholarlyCommons. https://repository.upenn.edu/prc_papers/390

For more information, please contact repository@pobox.upenn.edu. 


\title{
Regret, Portfolio Choice, and Guarantees in Defined Contribution Schemes
}

\begin{abstract}
We model how asset allocation decisions in a defined contribution (DC) pension plan might vary with participants' attitudes about risk and regret. We show that anticipated disutility from regret can have a potent effect on investment choices. Compared to a risk-averse investor, the investor who takes regret into account will hold more stock when the equity premium is low but less stock when the equity premium is high. We also assess how regret can influence a DC plan participant's view of rate-of-return guarantees, as measured by his willingness-to-pay. We find that regret increases the regret-averse investor's willingness to pay for a guarantee when the portfolio is relatively risky but decreases it when the portfolio is relatively safe.
\end{abstract}

\section{Keywords}

Regret, Investment, Retirement Saving, Guarantee

\section{Disciplines}

Economics 


\title{
Regret, Portfolio Choice, and Guarantees in Defined Contribution Schemes
}

\author{
Alexander Muermann, Olivia S. Mitchell, and Jacqueline M. Volkman
}

\author{
PRC WP 2005-17 \\ Pension Research Council Working Paper \\ Pension Research Council \\ The Wharton School, University of Pennsylvania \\ 3620 Locust Walk, 3000 SH-DH \\ Philadelphia, PA 19104-6302 \\ Tel: 215.898.7620 Fax: 215.898.0310 \\ Email: prc@wharton.upenn.edu \\ http://prc.wharton.upenn.edu/prc/prc.html
}

\begin{abstract}
All findings, interpretations, and conclusions of this paper represent the views of the author(s) and not those of the Wharton School or the Pension Research Council. The Council will publish a revised version of the conference papers; see http://prc.wharton.upenn.edu/prc/prc.html. Copyright 2005 C Pension Research Council of the Wharton School of the University of Pennsylvania. All rights reserved.
\end{abstract}




\title{
Regret, Portfolio Choice, and Guarantees in Defined Contribution Schemes $\diamond$
}

\author{
Alexander Muermann ${ }^{a, *}$, Olivia S. Mitchell ${ }^{a}$, Jacqueline M. Volkman ${ }^{\text {a }}$ \\ a The Wharton School, University of Pennsylvania, 3620 Locust Walk, Philadelphia, PA 19104, USA
}

This Version: September 2005

First Version: October 2003

\begin{abstract}
We model how asset allocation decisions in a defined contribution (DC) pension plan might vary with participants' attitudes about risk and regret. We show that anticipated disutility from regret can have a potent effect on investment choices. Compared to a risk-averse investor, the investor who takes regret into account will hold more stock when the equity premium is low but less stock when the equity premium is high. We also assess how regret can influence a DC plan participant's view of rate-of-return guarantees, as measured by his willingness-to-pay. We find that regret increases the regret-averse investor's willingness to pay for a guarantee when the portfolio is relatively risky but decreases it when the portfolio is relatively safe.
\end{abstract}

JEL classifications G11, G23, D81

Keywords Regret, Investment, Retirement Saving, Guarantee

Subject and Insurance Branch Categories IM50, IE13

${ }^{*}$ Corresponding author. Insurance and Risk Management Department, The Wharton School, University of Pennsylvania, 3010 SH-DH, 3620 Locust Walk, Philadelphia, PA 19104, USA, phone +1 215898 4751, fax +1 215898 0310, email: muermann@wharton.upenn.edu

$\diamond$ Funding for this research was provided by the Social Security Administration through a grant to the Michigan Retirement Research Center (MRRC), and by the Pension Research Council. An earlier version of this paper appeared as MRRC working paper 2003-060, October 2003, under the title "The Demand for Guarantees in Social Security Personal Retirement Accounts". For helpful suggestions we thank Marie-Eve Lachance. 


\section{Introduction}

This paper evaluates the portfolio allocation behavior of participants in defined contribution (DC) plans, taking account of the possibility that such pension plan investors may be influenced by the prospect of regret. For example, if the return on a specific asset turns out to be very high when a worker retires, he might regret not having allocated a large enough portion of his contributions to that asset. Conversely, if the stock market does poorly, the retiree might regret having invested in the stock market. Such anticipated disutility from regret is particularly important in the context of a DC pension, since most participants select an initial asset allocation when they join the plan but often do not manage their retirement accounts actively thereafter. ${ }^{1}$

Regret theory was developed by Loomes and Sugden (1982) and Bell (1982) and axiomatized by Sugden (1993) and Quiggin (1994). In that work, as here, regret is defined as the disutility of not having chosen the ex-post optimal alternative. Behavior compatible with such a preference structure has been observed in many contexts, where it often explains deviations from expected utility models traditionally used in the finance and insurance literature (cf Loomes and Sugden, 1987; Loomes,1988; Baron and Hershey, 1988; Loomes et al. 1992; Starmer and Sugden, 1993; Connolly and Reb, 2003). Recently regret theory has been applied by Braun and Muermann (2004) to insurance demand, and by Gollier and Salanie (2005) to risk-sharing and asset pricing in a complete market setting. To date, researchers have not focused on how regret might alter investor behavior.

In the present paper, our goal is to examine the effect of regret on investment behavior and participants' value of guarantees in DC pension plans. Section 2 assesses how regret can influence the asset allocation decision in a retirement account, between risk-free and risky assets. To protect retirees against capital market risk, some have suggested that participants would benefit from financial products that will protect them against down-side asset fluctuations (c.f. Lachance and Mitchell, 2003). It is interesting that Germany and Japan recently mandated that DC participants be offered a principal-guaranteed account, on the grounds that this will make defined contribution plans more attractive to unsophisticated participants (Maurer and Schlag, 2003). In Section 3, we evaluate the impact of regret on participants' willingness-to-pay for a guarantee on the risky asset. Section 4 offers concluding remarks and areas for further research. All proofs are in the Appendix.

\footnotetext{
${ }^{1}$ Agnew et al (2003), in a study of 401k plan participants, report that the vast majority (87 percent) of participants had no annual trades; over a four year period, only a single trade took place per participant. Similarly, Ameriks and Zeldes (2000) show that almost half of all TIAA-CREF participants made no changes in their asset allocations at all during the decade 1987-96. Additionally, Madrian and Shea (2001) find employees procrastinate in making or implementing savings decisions in 401(k) plans of large U.S. corporations.
} 


\section{The Impact of Regret on Portfolio Allocation}

We begin by examining investment behavior in a DC setting under regret aversion. Suppose an investor has initial wealth $w_{0}$ which he can allocate between a risky and a risk-free asset. The return of the risky asset is given by a random variable $R$ which is distributed according to some cumulative distribution function $F$, whereas the risk-free asset yields a deterministic return $r_{f}$. In making his portfolio choice, the investor takes into account the fact that he may regret having made an investment decision that proves to be suboptimal ex-post. For example, if the return on the risky asset turns out to be very high, the investor might regret not having allocated his total wealth to the risky asset. In the contrary case, if the return of the risky asset turns out to be very low or negative, the investor could regret having allocated any wealth to the risky asset at all.

To examine the impact of regret on the participant's ex-ante allocation of wealth, we follow the approach of Braun and Muermann (2004) to pose the investor's preferences as a two-attribute Bernoulli utility function

$$
u_{k}(w)=u(w)-k \cdot g\left(u\left(w^{\max }\right)-u(w)\right) .
$$

Here $w=w_{0}\left(1+\alpha R+(1-\alpha) r_{f}\right)$ is the actual level of wealth and $w^{\max }$ is the ex-post optimal level of final wealth, i.e. the level of wealth that results from the optimal ex-ante allocation had the investor known the realized return of the risky asset. The first attribute accounts for risk aversion and is characterized by the investor's utility function $u(\cdot)$ with $u^{\prime}>0$ and $u^{\prime \prime}<0$. The second attribute relates to the fact that the investor is concerned about the prospect of regret. The function $g(\cdot)$ measures the amount of regret that the investor experiences, which depends on the difference between the value he assigns to the ex-post optimal level of wealth $w^{\max }$ that he could have achieved, and the value that he assigns to his actual final level of wealth $w$. The parameter $k \geq 0$ measures the importance of the second attribute "regret" relative to the traditional first attribute expressive of risk aversion. We assume that $g(\cdot)$ is increasing and strictly convex, i.e. $g^{\prime}>0$ and $g^{\prime \prime}>0$, which implies regret-aversion. For $k=0$, the investor would simply be a traditional risk-averse expected utility maximizer, i.e. $u_{0}(w)=u(w)$.

To determine the ex-post optimal level of final wealth $w^{\max }$ for this investor, we must distinguish the cases when the risky asset's realized return exceeds the risk-free rate, $R \geq r_{f}$, from when $R<r_{f}$. In the first case, the regret-averse investor would have wanted to invest all wealth in the risky asset, whereas in the second case it 
would have been optimal to invest all wealth in the risk-free asset. Therefore

$$
w^{\max }=\left\{\begin{array}{lcc}
w_{0}(1+R) & & R \geq r_{f} \\
w_{0}\left(1+r_{f}\right) & & R<r_{f}
\end{array} .\right.
$$

We now compare how anticipation of regret influences the investor's optimal asset allocation. Let $\alpha_{k}^{*}$ denote the optimal fraction invested in the risky asset by an investor with regret parameter $k \geq 0$ where $\alpha_{0}^{*}=\alpha^{*}$. The following proposition shows that a regret-averse investor will always "hedge away from the extremes." In other words, compared to a traditional risk-averse investor, he will select a riskier portfolio allocation if the equity premium is low, and a more moderate portfolio allocation if the equity premium is high.

Proposition 1 If $E[R]-r_{f}=0$ then $\alpha_{k}^{*}>0$ for all $k>0$ whereas $\alpha_{0}^{*}=0$. If $E[R]-r_{f}=\frac{\operatorname{Cov}\left(-R, u^{\prime}\left(w_{0}(1+R)\right)\right)}{E\left[u^{\prime}\left(w_{0}(1+R)\right)\right]}$ then $\alpha_{k}^{*}<1$ for all $k>0$ whereas $\alpha_{0}^{*}=1$.

Proof. See Appendix A.1.

The regret-averse investor always invests a positive amount of his wealth in the risky asset (here, termed stocks), even if the equity premium equals zero; by contrast, a risk-averse investor would hold all risk-free assets (here, termed bonds) in that case. Additionally, for a sufficiently large equity premium, the regret-averse investor always invests a positive amount in the risk-free asset, whereas the risk-averse investor holds all stocks. This may be explained intuitively, by noting that taking an extreme position, e.g. all riskless, exposes the investor to the possibility of facing extreme regret if stocks do well. By avoiding all bonds, the worker will feel less regret if stocks do well but, in return, he will feel some regret if they do poorly. Regret aversion, i.e. convexity of $g$, leads to suboptimality of extreme decisions.

In the following proposition, we show that higher regret amplifies the effect of "hedging one's bet."

Proposition 2 If the investor weights regret more strongly, relative to risk aversion, as measured by $k$, then for $E[R]-r_{f}=0$ he invests more in the risky asset, whereas for $E[R]-r_{f}=\frac{\operatorname{Cov}\left(-R, u^{\prime}\left(w_{0}(1+R)\right)\right)}{E\left[u^{\prime}\left(w_{0}(1+R)\right)\right]}$ he invests less in the risky asset, i.e.

$$
\begin{array}{lll}
\frac{\partial \alpha_{k}^{*}}{\partial k}>0 & \text { if } & E[R]-r_{f}=0 \\
\frac{\partial \alpha_{k}^{*}}{\partial k}<0 & \text { if } & E[R]-r_{f}=\frac{\operatorname{Cov}\left(-R, u^{\prime}\left(w_{0}(1+R)\right)\right)}{E\left[u^{\prime}\left(w_{0}(1+R)\right)\right]}
\end{array} .
$$

Proof. See Appendix A.2. 
In other words, the more regret-averse the participant, the more likely he will be to hold stock in his portfolio as long as the equity premium, $E[R]-r_{f}$, is low. Conversely, he will hold less stock if the equity premium is high.

In the next proposition, we show that there exists a risk-free rate of return $\widehat{r_{f}}$, and therefore a level of equity premium, where regret has no impact on the investor's optimal fraction invested in the risky asset. That is, a regret-averse investor holds the same portfolio allocation as a risk-averse investor, at that equity premium.

Proposition 3 There exists $\widehat{r_{f}}$ such that $0<E[R]-\widehat{r_{f}}<\frac{\operatorname{Cov}\left(-R, u^{\prime}\left(w_{0}(1+R)\right)\right)}{E\left[u^{\prime}\left(w_{0}(1+R)\right)\right]}$ and $\alpha_{k}^{*}=\alpha_{0}^{*}$ for all $k>0$.

\section{Proof. See Appendix A.3.}

In other words, for some intermediate level of the equity premium, a regret-averse investor chooses a portfolio allocation as if he did not consider regret.

We summarize our findings in Figure 1. The equity premium is on the x-axis and the optimal level of investment in the risky asset is depicted on the y-axis. With a zero equity premium, the risk-averse investor would invest all of his wealth in the risk-free asset $\left(\alpha_{0}^{*}=0\right)$. By contrast, the regret-averse investor would place some of his wealth in the stock $\left(\alpha_{k}^{*}>0\right)$. As the level of regret aversion rises, i.e. $k_{2}>k_{1}$, the amount of wealth invested in the stock increases. With a relatively large equity premium, the risk-averse investor allocates all of his wealth to stock $\left(\alpha_{0}^{*}=1\right)$, while the regret-averse investor invests some money in the risk-free asset $\left(\alpha_{k}^{*}<1\right)$. As the level of regret aversion increases, with a high equity premium, the amount of wealth invested in stock decreases.

Our results therefore imply that pension plan participants with regret-averse preferences will select portfolio allocations "less extreme" than those predicted by conventional expected utility. If a very risky portfolio were selected by a purely risk-averse worker, his regret-averse counterpart will elect a less risky portfolio; conversely, when the purely risk-averse individual is predicted to chose a non-risky portfolio, the regret-averse individual would prefer a riskier portfolio. In essence, individuals who are regret-averse will tend to "hedge their bets," taking into account the possibility that their decisions may turn out to be ex-post suboptimal. Note that for an equity premium that is sufficiently high, these predictions can help explain the equity premium puzzle. 


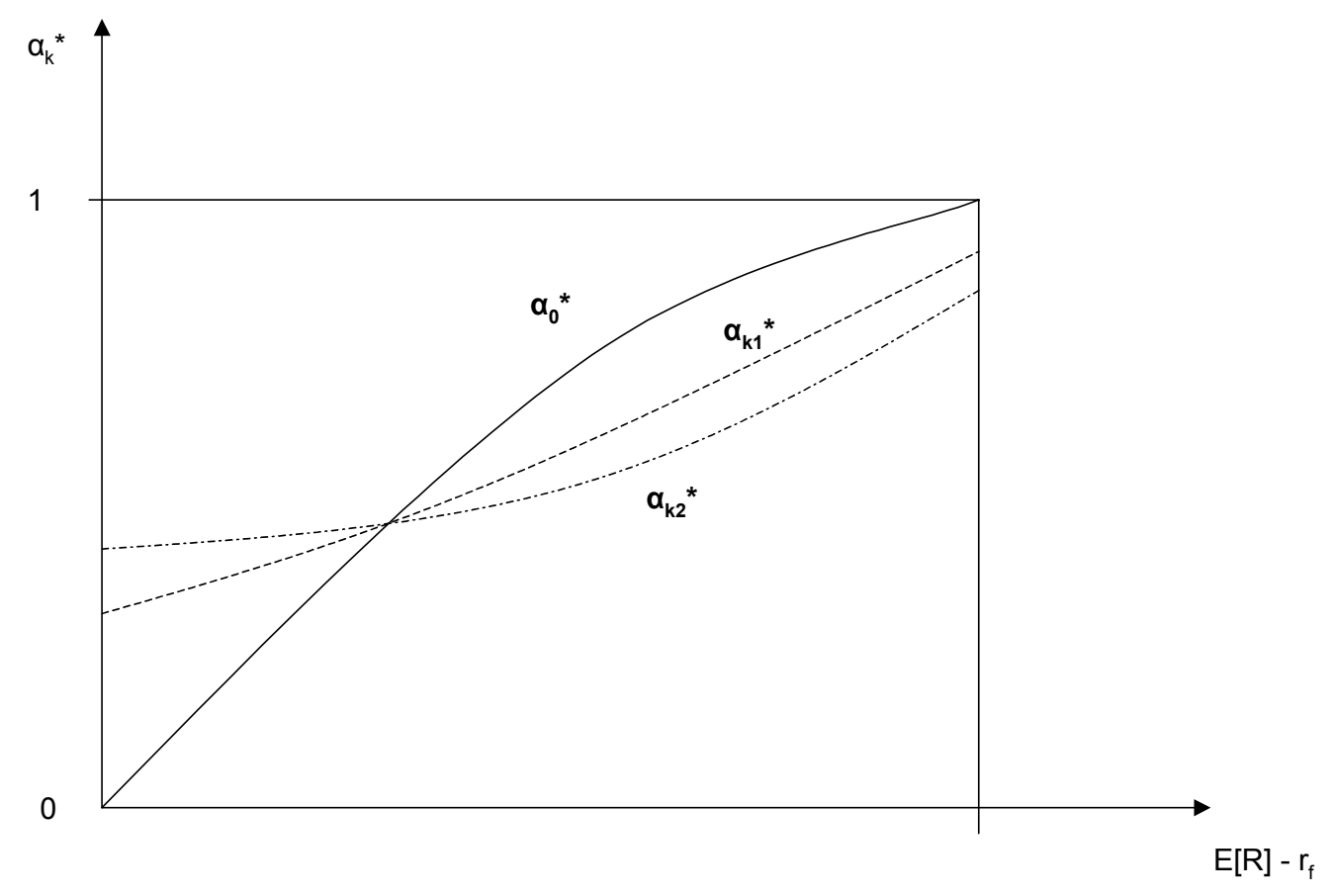

Figure 1: Asset Allocation under Regret Aversion

\section{Guarantees: Mitigating Regret and Willingness-To-Pay}

Next we assume that a guaranteed rate of return on the risky asset is made available. Guarantees may help mitigate the regret experienced by investors, by protecting their wealth in states of the world where realized stock outcomes are poor. The benefit of a guarantee is valuable for high levels of investment in the risky asset. For example, an investor with a substantial portion of his wealth in stocks who finds himself in a state of the world with a low realized return on this investment would experience a great deal of regret from having made such a decision. Of course, a guarantee on an investment would offer some wealth protection, which would reduce the individual's feeling of regret. Certainly this regret mitigation feature of a guarantee is most beneficial when the fraction of wealth invested in the risky asset is high. On the other hand, a guarantee also introduces an additional cost to regret-averse investors. Ex-post, it is optimal to have either invested all wealth in the risky asset, or all in the risk-free asset. Buying a guarantee therefore could exacerbate ex-ante regret.

A range of pension guarantee mechanisms might be contemplated for DC pension plans, though in practice they tend to take the form of either a rate of return guarantee or a minimum benefit guarantee. In the present 
paper, we focus on the former structure, wherein a pension manager commits to return to the worker his or her contributions plus some stipulated rate of return. A variation on this is a principal guarantee, simply equivalent to guaranteeing a nominal rate of return of zero percent. By contrast, Feldstein and Samwick (2001) have suggested an alternative for the US, namely a real principal guarantee; a more generous plan still might promise to pay back contributions plus the 10-year Treasury bond return.

The costs of providing such guarantees depends, of course, on how the guarantees are designed. ${ }^{2}$ First, it matters how often the promise must be kept. For example, it might be sufficient to structure the program so that the minimum return is evaluated only at the worker's retirement date, rather than annually or more frequently. ${ }^{3}$ Second, the cost of the pension guarantee depends on how much investment risk is borne by the DC plan investor. Participants could make the guarantee more valuable, and hence more costly, if they have an opportunity to chose riskier DC plan assets after receiving the guarantee. This moral hazard problem has been recognized by Bodie and Merton (1993) and Smetters (2002), among others, and it has prompted some countries to impose portfolio restrictions on investors' DC pension asset allocations. For instance, Mexico and Chile originally required that DB plan participants hold an all-bond portfolio. Alternatively, employers could offer workers in DC plans some protection from market fluctuations without mandating a risk-free portfolio. This can be accomplished by providing a guaranteed return on the risky asset (Turner and Rajnes, 2003; Walliser, 2003).

In this section, we examine how investors might value a pension guarantee by comparing the Willingness-ToPay (WTP) for such a guarantee for a regret-averse versus a risk-averse investor. The WTP is derived from an indifference relation between a portfolio with and without the guarantee, and thus it provides a measure of how much an individual values the guarantee. ${ }^{4}$

Let $r_{g} \geq-1$ be the guaranteed return on the risky asset. The return of this contingent contract is therefore $R_{g}=\max \left(R, r_{g}\right) .^{5} \quad$ As noted above, the guarantee does not alter the ex-post optimal level of final wealth $w^{\max }$. The ex-post optimal decision is to invest one's entire portfolio in the risky asset, if its realized return is above the risk-free rate of return, and all of it in the risk-free asset if otherwise, i.e. $w^{\max }=w_{0}\left(1+\max \left(R, r_{f}\right)\right)$.

\footnotetext{
${ }^{2}$ See, for instance, Lachance et al. (2003) and Mitchell and Smetters (2003).

${ }^{3}$ Pennachi (1999) and Fischer (1999) note that a more frequent minimum bar could be set, as in Chile, where pension plans must meet an annual minimum threshold, or in Columbia, where three-year periods are used.

${ }^{4}$ Boulier et al. (2001) and Deelstra et al. (2003) derive optimal investment strategies of DC plan managers in the presence of minimum guarantees. In this paper, we are concerned with how plan participants differently value guarantees depending on whether they are regret-averse or not.

${ }^{5}$ Alternatively, the guaranteed return could apply to the entire portfolio. Our results extend to this case by redefining $r_{g}$ accordingly.
} 
Let $P_{k}\left(r_{g}, \bar{\alpha}\right)$ denote the maximum price the investor with regret parameter $k \geq 0$ is willing to pay for the guaranteed return $r_{g}$, if his risky asset allocation were fixed at $\bar{\alpha} \cdot{ }^{6}$ His WTP $P_{k}\left(r_{g}, \bar{\alpha}\right)$ is then determined by the following indifference equation

$$
E\left[u_{k}\left(w_{0}\left(1+\bar{\alpha} R+(1-\bar{\alpha}) r_{f}\right)\right)\right]=E\left[u_{k}\left(w_{0}-P_{k}\left(r_{g}, \bar{\alpha}\right)\right)\left(1+\bar{\alpha} R_{g}+(1-\bar{\alpha}) r_{f}\right)\right]
$$

Obviously, if no guarantee is provided, $r_{g}=-1$, the investor's WTP is zero, i.e. $P_{k}(-1, \bar{\alpha})=0$ for all $0 \leq \bar{\alpha} \leq 1$. In addition, if the investor's wealth were fixed all in bonds, his WTP for the stock guarantee is zero, i.e. $P_{k}\left(r_{g}, 0\right)=0$ for all $-1 \leq r_{g} \leq r_{f}$.

In the following proposition, we show that a regret-averse investor values the guarantee less than the riskaverse investor, when the fraction of wealth invested in the risky asset is low. However, if the fraction of wealth invested in the risky asset is high, and the level of guaranteed return is low, a regret-averse investor will find the guarantee more valuable than the risk-averse investor.

Proposition $4 P_{k}\left(r_{g}, \bar{\alpha}\right)<P_{0}\left(r_{g}, \bar{\alpha}\right)$ for low levels of $\bar{\alpha}$ and all $r_{g}$ and $P_{k}\left(r_{g}, \bar{\alpha}\right)>P_{0}\left(r_{g}, \bar{\alpha}\right)$ for high levels of $\bar{\alpha}$ and low levels of $r_{g}$.

Proof. See Appendix A.4.

If the portfolio share in the risky asset is low, the regret-averse investor would be willing to pay less for the guarantee than would a risk-averse investor. In this case, the benefits of the guarantee in mitigating regret are low and outweighed by its added "regret cost" through the price. In contrast, when investment in the risky asset is high and the guaranteed rate of return low, the benefits of regret mitigation would be high, outweighing its cost. A regret-averse investor then values the guarantee more than a risk-averse investor.

\section{Conclusions and Future Research}

The last three decades have brought a dramatic transformation in the pension institution, with defined benefit plans being replaced by defined contribution plans. In the traditional DB context, employers hired sophisticated money managers to make asset allocation decisions; in DC pensions, by contrast, individual participants now bear the risk and consequences of their pension asset allocation patterns. Recent research in behavioral finance

\footnotetext{
${ }^{6}$ We fix the investor's portfolio allocation to mitigate the moral hazard problem of investors rebalancing their portfolio due to the provided guarantee.
} 
suggests that workers faced with having to save and invest for their own retirement often fail to behave as conventional expected utility models would predict. $^{7}$

This paper shows how regret can influence investor portfolio allocations in such individually-managed DC pensions. We also illustrate how much a regret-averse investor might be willing to pay for a rate of return guarantee on the risky asset, given a fixed portfolio allocation. Our results show that regret moves investors' decisions away from the extremes, if no guarantee is present. That is, investors who take regret into account will hold more stock when the equity premium is low, but less stock when the equity premium is high. This result may explain the equity premium puzzle, since for a sufficiently high equity premium a regret-averse investor will hold less stock than a risk-averse investor. We also show that regret-averse investors value return guarantees less than purely risk-averse investors, when the investment in the risky asset is small. Conversely, regret-averse investors value return guarantees more than risk-averse investors when the investment in the risky asset is large and the return guarantee is small. This work therefore has implications for efforts to add a DC component to a national Social Security system and the likely importance of guarantees in this context (c.f. Cogan and Mitchell, 2003).

Extensions of our research might be fruitful. For instance, van der Hoek and Sherris (2001) have proposed a risk measure that has a concave distortion function above a given reference point, but a convex distortion function below that point. It would be interesting to translate their work to the regret context, using the ex-post optimal level of wealth as the relevant reference point. Additionally, we could investigate what happens if the fraction of the DC pension plan invested in risky assets cannot be fixed ex-ante. In this case, it would be of interest to ask whether there is an incentive-compatible contract which would still permit an attractive guarantee, without being prohibitively expensive.

\footnotetext{
${ }^{7}$ Mitchell and Utkus (2004) review several instances of such problems in the DC pension context.
} 


\section{A Appendix}

\section{A.1 Proof of Proposition 1}

The investor's optimization program is

$$
\max _{\alpha \in[0,1]} E\left[u_{k}(w(\alpha))\right]=E\left[u(w(\alpha))-k \cdot g\left(u\left(w^{\max }\right)-u(w(\alpha))\right)\right]
$$

where $w(\alpha)=w_{0}\left(1+\alpha R+(1-\alpha) r_{f}\right)$ and $w^{\max }=w_{0}\left(1+\max \left(R, r_{f}\right)\right)$ denote the investor's final level and ex-post optimal level of wealth. The first- and second-order conditions for (2) are

$$
\frac{d E\left[u_{k}(w(\alpha))\right]}{d \alpha}=E\left[w_{0}\left(R-r_{f}\right) u^{\prime}(w(\alpha))\left(1+k g^{\prime}\left(u\left(w^{\max }\right)-u(w(\alpha))\right)\right)\right]=0
$$

and

$$
\begin{aligned}
\frac{d^{2} E\left[u_{k}(w(\alpha))\right]}{d \alpha^{2}}= & E\left[w_{0}^{2}\left(R-r_{f}\right)^{2} u^{\prime \prime}(w(\alpha))\left(1+k g^{\prime}\left(u\left(w^{\max }\right)-u(w(\alpha))\right)\right)\right] \\
& -E\left[w_{0}^{2}\left(R-r_{f}\right)^{2} k u^{\prime 2}(w(\alpha)) g^{\prime \prime}\left(u\left(w^{\max }\right)-u(w(\alpha))\right)\right] \\
< & 0 .
\end{aligned}
$$

As $E\left[u_{k}(w(\alpha))\right]$ is strictly concave in $\alpha$, any solution of (3) determines the unique global maximum. The first derivative (3) can be decomposed into

$$
\begin{aligned}
\frac{d E\left[u_{k}(w(\alpha))\right]}{d \alpha}= & \frac{d E\left[u_{0}(w(\alpha))\right]}{d \alpha}+\int_{-1}^{r_{f}} k w_{0}\left(r-r_{f}\right) u^{\prime}(w(\alpha)) g^{\prime}(u(w(0))-u(w(\alpha))) d F(r) \\
& +\int_{r_{f}}^{\infty} k w_{0}\left(r-r_{f}\right) u^{\prime}(w(\alpha)) g^{\prime}(u(w(1))-u(w(\alpha))) d F(r)
\end{aligned}
$$

Evaluating the first derivative at $\alpha=0$ and $\alpha=1$ yields

$$
\begin{aligned}
\left.\frac{d E\left[u_{k}(w(\alpha))\right]}{d \alpha}\right|_{\alpha=0}= & \left.\frac{d E\left[u_{0}(w(\alpha))\right]}{d \alpha}\right|_{\alpha=0}+k w_{0} g^{\prime}(0) u^{\prime}(w(0)) \int_{-1}^{r_{f}}\left(r-r_{f}\right) d F(r)+k w_{0} u^{\prime}(w(0)) \\
& +\int_{r_{f}}^{\infty}\left(r-r_{f}\right) g^{\prime}(u(w(1))-u(w(0))) d F(r) \\
> & \left.\frac{d E\left[u_{0}(w(\alpha))\right]}{d \alpha}\right|_{\alpha=0}+k w_{0} g^{\prime}(0) u^{\prime}(w(0))\left(E[R]-r_{f}\right) \\
= & w_{0} u^{\prime}(w(0))\left(E[R]-r_{f}\right)\left(1+k g^{\prime}(0)\right)
\end{aligned}
$$


and

$$
\begin{aligned}
\left.\frac{d E\left[u_{k}(w(\alpha))\right]}{d \alpha}\right|_{\alpha=1}= & \left.\frac{d E\left[u_{0}(w(\alpha))\right]}{d \alpha}\right|_{\alpha=1}+\int_{-1}^{r_{f}} k w_{0}\left(r-r_{f}\right) u^{\prime}(w(1)) g^{\prime}(u(w(0))-u(w(1))) d F(r) \\
& +\int_{r_{f}}^{\infty} k w_{0}\left(r-r_{f}\right) u^{\prime}(w(1)) g^{\prime}(0) d F(r) \\
< & \left.\frac{d E\left[u_{0}(w(\alpha))\right]}{d \alpha}\right|_{\alpha=1}+k w_{0} g^{\prime}(0) E\left[\left(R-r_{f}\right) u^{\prime}(w(1))\right] \\
= & w_{0} E\left[\left(R-r_{f}\right) u^{\prime}(w(1))\right]\left(1+k g^{\prime}(0)\right) .
\end{aligned}
$$

If $E[R]-r_{f}=0$ then $\left.\frac{d E\left[u_{k}(w(\alpha))\right]}{d \alpha}\right|_{\alpha=0}>0$ for all $k>0$, and if $E[R]-r_{f}=\frac{\operatorname{Cov}\left(-R, u^{\prime}\left(w_{0}(1+R)\right)\right)}{E\left[u^{\prime}\left(w_{0}(1+R)\right)\right]}$ then $\left.\frac{d E\left[u_{k}(w(\alpha))\right]}{d \alpha}\right|_{\alpha=1}<0$ for all $k>0$. This implies that $\alpha_{k}^{*}>0$ for all $k>0$ in the first situation and $\alpha_{k}^{*}<1$ for all $k>0$ in the latter.

\section{A.2 Proof of Proposition 2}

Taking the total differential of the first-order condition (3) with respect to $\alpha$ and $k$ leads to

$$
\left.\frac{\partial^{2} E\left[u_{k}(w(\alpha))\right]}{\partial \alpha^{2}}\right|_{\alpha=\alpha_{k}^{*}} \cdot d \alpha+\left.\frac{\partial^{2} E\left[u_{k}(w(\alpha))\right]}{\partial \alpha \partial k}\right|_{\alpha=\alpha_{k}^{*}} \cdot d k=0
$$

and therefore

$$
\frac{\partial \alpha_{k}^{*}}{\partial k}=-\frac{\left.\frac{\partial^{2} E\left[u_{k}(w(\alpha))\right]}{\partial \alpha \partial k}\right|_{\alpha=\alpha_{k}^{*}}}{\left.\frac{\partial^{2} E\left[u_{k}(w(\alpha))\right]}{\partial \alpha^{2}}\right|_{\alpha=\alpha_{k}^{*}}} .
$$

$\left.\operatorname{As} \frac{\partial^{2} E\left[u_{k}(w(\alpha))\right]}{\partial \alpha^{2}}\right|_{\alpha=\alpha_{k}^{*}}<0$

$$
\operatorname{sign}\left(\frac{\partial \alpha_{k}^{*}}{\partial k}\right)=\operatorname{sign}\left(\left.\frac{\partial^{2} E\left[u_{k}(w(\alpha))\right]}{\partial \alpha \partial k}\right|_{\alpha=\alpha_{k}^{*}}\right) .
$$

The cross-partial derivative equals

$$
\left.\frac{\partial^{2} E\left[u_{k}(w(\alpha))\right]}{\partial \alpha \partial k}\right|_{\alpha=\alpha_{k}^{*}}=E\left[w_{0}\left(R-r_{f}\right) u^{\prime}\left(w\left(\alpha_{k}^{*}\right)\right) g^{\prime}\left(u\left(w^{\max }\right)-u\left(w\left(\alpha_{k}^{*}\right)\right)\right)\right] .
$$

From the FOC (3) we imply

$$
\left.\frac{d E\left[u_{k}(w(\alpha))\right]}{d \alpha}\right|_{\alpha=\alpha_{k}^{*}}=\left.\frac{d E\left[u_{0}(w(\alpha))\right]}{d \alpha}\right|_{\alpha=\alpha_{k}^{*}}+\left.k \cdot \frac{\partial^{2} E\left[u_{k}(w(\alpha))\right]}{\partial \alpha \partial k}\right|_{\alpha=\alpha_{k}^{*}} .
$$

As $\left.\frac{d E\left[u_{k}(w(\alpha))\right]}{d \alpha}\right|_{\alpha=\alpha_{k}^{*}}=0$ we have

$$
\operatorname{sign}\left(\frac{\partial \alpha_{k}^{*}}{\partial k}\right)=\operatorname{sign}\left(\left.\frac{\partial^{2} E\left[u_{k}(w(\alpha))\right]}{\partial \alpha \partial k}\right|_{\alpha=\alpha_{k}^{*}}\right)=-\operatorname{sign}\left(\left.\frac{d E\left[u_{0}(w(\alpha))\right]}{d \alpha}\right|_{\alpha=\alpha_{k}^{*}}\right) .
$$

If $E[R]-r_{f}=0$ then $\alpha_{0}^{*}=0$ and $\alpha_{k}^{*}>0$ for all $k>0$ according to Proposition 1 . This implies $\left.\frac{d E\left[u_{0}(w(\alpha))\right]}{d \alpha}\right|_{\alpha=\alpha_{k}^{*}>0}<$ 0 and thus $\frac{\partial \alpha_{k}^{*}}{\partial k}>0$ by (5). If $E[R]-r_{f}=\frac{\operatorname{Cov}\left(-R, u^{\prime}\left(w_{0}(1+R)\right)\right)}{E\left[u^{\prime}\left(w_{0}(1+R)\right)\right]}$ then $\alpha_{0}^{*}=1$ and $\alpha_{k}^{*}<1$ for all $k>0$ according 
to Proposition 1. This implies $\left.\frac{d E\left[u_{0}(w(\alpha))\right]}{d \alpha}\right|_{\alpha=\alpha_{k}^{*}<1}>0$ and thus $\frac{\partial \alpha_{k}^{*}}{\partial k}<0$ by (5).

\section{A.3 Proof of Proposition 3}

For any fixed $k>0$ we have have shown in Proposition 1 that

$$
\begin{array}{lll}
\alpha_{k}^{*}>0 \text { and } \alpha_{0}^{*}=0 & \text { if } & E[R]-r_{f}=0 \\
\alpha_{k}^{*}<1 \text { and } \alpha_{0}^{*}=1 & \text { if } & E[R]-r_{f}=\frac{\operatorname{Cov}\left(-R, u^{\prime}\left(w_{0}(1+R)\right)\right)}{E\left[u^{\prime}\left(w_{0}(1+R)\right)\right]}
\end{array} .
$$

The Intermediate Value Theorem implies that there exists $\widehat{r_{f}}(k)$ with $E[R]-\frac{\operatorname{Cov}\left(-R, u^{\prime}\left(w_{0}(1+R)\right)\right)}{E\left[u^{\prime}\left(w_{0}(1+R)\right)\right]}<\widehat{r_{f}}(k)<E[R]$ such that $\alpha_{k}^{*}=\alpha_{0}^{*}$ at this risk-free rate of return. The following first order conditions

$$
\left.\frac{d E[u(w(\alpha))]}{d \alpha}\right|_{\alpha=\alpha_{0}^{*}}=E\left[w_{0}\left(R-\widehat{r_{f}}(k)\right) u^{\prime}\left(w\left(\alpha_{0}^{*}\right)\right)\right]=0
$$

and

$$
\left.\frac{d E\left[u_{k}(w(\alpha))\right]}{d \alpha}\right|_{\alpha=\alpha_{0}^{*}}=E\left[w_{0}\left(R-\widehat{r_{f}}(k)\right) u^{\prime}\left(w\left(\alpha_{0}^{*}\right)\right)\left(1+k g^{\prime}\left(u\left(w^{\max }\right)-u\left(w\left(\alpha_{0}^{*}\right)\right)\right)\right)\right]=0
$$

lead to the condition

$$
E\left[w_{0}\left(R-\widehat{r_{f}}(k)\right) u^{\prime}\left(w\left(\alpha_{0}^{*}\right)\right) g^{\prime}\left(u\left(w^{\max }\right)-u\left(w\left(\alpha_{0}^{*}\right)\right)\right)\right]=0 .
$$

As this condition is independent of $k$ we conclude that $\widehat{r_{f}}(k)=\widehat{r_{f}}$ for all $k \geq 0$.

\section{A.4 Proof of Proposition 4}

The WTP $P_{k}\left(r_{g}, \bar{\alpha}\right)$ of an investor is implicitly defined through (1)

$$
E\left[u_{k}\left(w_{0} R(-1, \bar{\alpha})\right)\right]=E\left[u_{k}\left(\left(w_{0}-P_{k}\left(r_{g}, \bar{\alpha}\right)\right) R\left(r_{g}, \bar{\alpha}\right)\right)\right]
$$

where $R\left(r_{g}, \bar{\alpha}\right)=1+\bar{\alpha} R_{g}+(1-\bar{\alpha}) r_{f}$ and $R_{g}=\max \left(R, r_{g}\right)$. The regret-averse investor is willing to pay less for the guarantee than the risk-averse investor, i.e. $P_{k}\left(r_{g}, \bar{\alpha}\right)<P_{0}\left(r_{g}, \bar{\alpha}\right)$ for all $r_{g}$, if and only if

$$
E\left[u\left(\left(w_{0}-P_{k}\left(r_{g}, \bar{\alpha}\right)\right) R\left(r_{g}, \bar{\alpha}\right)\right)\right]>E\left[u\left(\left(w_{0}-P_{0}\left(r_{g}, \bar{\alpha}\right)\right) R\left(r_{g}, \bar{\alpha}\right)\right)\right]=E\left[u\left(w_{0} R(-1, \bar{\alpha})\right)\right]
$$

for all $r_{g}$. Define the function $f:[0,1] \rightarrow \mathbb{R}$ as

$$
f(\bar{\alpha})=E\left[u\left(\left(w_{0}-P_{k}\left(r_{g}, \bar{\alpha}\right)\right) R\left(r_{g}, \bar{\alpha}\right)\right)\right]-E\left[u\left(w_{0} R(-1, \bar{\alpha})\right)\right] .
$$

For $\bar{\alpha}=0$ we have $f(0)=0$. To prove that $P_{k}\left(r_{g}, \bar{\alpha}\right)<P_{0}\left(r_{g}, \bar{\alpha}\right)$ for small $\bar{\alpha}$ and all $r_{g}$ we thus have to show that $f^{\prime}(0)>0$. Differentiating $f$ with respect to $\bar{\alpha}$ yields

$$
f^{\prime}(\bar{\alpha})=\left[\begin{array}{c}
-\frac{\partial P_{k}}{\partial \bar{\alpha}} E\left[R\left(r_{g}, \bar{\alpha}\right) u^{\prime}\left(\left(w_{0}-P_{k}\left(r_{g}, \bar{\alpha}\right)\right) R\left(r_{g}, \bar{\alpha}\right)\right)\right] \\
+E\left[\left(w_{0}-P_{k}\left(r_{g}, \bar{\alpha}\right)\right)\left(R_{g}-r_{f}\right) u^{\prime}\left(\left(w_{0}-P_{k}\left(r_{g}, \bar{\alpha}\right)\right) R\left(r_{g}, \bar{\alpha}\right)\right)\right] \\
-E\left[w_{0}\left(R-r_{f}\right) u^{\prime}\left(w_{0} R(-1, \bar{\alpha})\right)\right]
\end{array}\right]
$$

and thus

$$
\left.f^{\prime}(0)=u^{\prime}\left(w_{0}\left(1+r_{f}\right)\right)\left[-\left.\frac{\partial P_{k}\left(r_{g}, \bar{\alpha}\right)}{\partial \bar{\alpha}}\right|_{\bar{\alpha}=0}\left(1+r_{f}\right)+w_{0} E\left[\left(R_{g}-R\right)\right)\right]\right] .
$$


Differentiating (1) with respect to $\bar{\alpha}$ implies

$$
\begin{aligned}
& E\left[w_{0}\left(R-r_{f}\right) u^{\prime}\left(w_{0} R(-1, \bar{\alpha})\right)\left(1+k g^{\prime}\left(u\left(w^{\max }\right)-u\left(w_{0} R(-1, \bar{\alpha})\right)\right)\right)\right] \\
= & {\left[\begin{array}{c}
-\frac{\partial P_{k}}{\partial \bar{\alpha}} E\left[R\left(r_{g}, \bar{\alpha}\right) u^{\prime}\left(\left(w_{0}-P_{k}\right) R\left(r_{g}, \bar{\alpha}\right)\right)\left(1+k g^{\prime}\left(u\left(w^{\max }\right)-u\left(\left(w_{0}-P_{k}\right) R\left(r_{g}, \bar{\alpha}\right)\right)\right)\right)\right] \\
+E\left[\left(w_{0}-P_{k}\right)\left(R_{g}-r_{f}\right) u^{\prime}\left(\left(w_{0}-P_{k}\right) R\left(r_{g}, \bar{\alpha}\right)\right)\left(1+k g^{\prime}\left(u\left(w^{\max }\right)-u\left(\left(w_{0}-P_{k}\right) R\left(r_{g}, \bar{\alpha}\right)\right)\right)\right)\right]
\end{array}\right] }
\end{aligned}
$$

where $P_{k}=P_{k}\left(r_{g}, \bar{\alpha}\right)$. For $\bar{\alpha}=0$ we get

$$
\begin{aligned}
& w_{0} u^{\prime}\left(w_{0}\left(1+r_{f}\right)\right) E\left[\left(R-r_{f}\right)\left(1+k g^{\prime}\left(u\left(w^{\max }\right)-u\left(w_{0}\left(1+r_{f}\right)\right)\right)\right)\right] \\
= & {\left[\begin{array}{c}
-\left.\frac{\partial P_{k}\left(r_{g}, \bar{\alpha}\right)}{\partial \bar{\alpha}}\right|_{\bar{\alpha}=0}\left(1+r_{f}\right) u^{\prime}\left(w_{0}\left(1+r_{f}\right)\right) E\left[\left(1+k g^{\prime}\left(u\left(w^{\max }\right)-u\left(w_{0}\left(1+r_{f}\right)\right)\right)\right)\right] \\
+w_{0} u^{\prime}\left(w_{0}\left(1+r_{f}\right)\right) E\left[\left(R_{g}-r_{f}\right)\left(1+k g^{\prime}\left(u\left(w^{\max }\right)-u\left(w_{0}\left(1+r_{f}\right)\right)\right)\right)\right]
\end{array}\right] }
\end{aligned}
$$

which implies

$$
\left.\frac{\partial P_{k}\left(r_{g}, \bar{\alpha}\right)}{\partial \bar{\alpha}}\right|_{\bar{\alpha}=0}=\frac{w_{0} E\left[\left(R_{g}-R\right)\left(1+k g^{\prime}\left(u\left(w^{\max }\right)-u\left(w_{0}\left(1+r_{f}\right)\right)\right)\right)\right]}{\left(1+r_{f}\right) E\left[\left(1+k g^{\prime}\left(u\left(w^{\max }\right)-u\left(w_{0}\left(1+r_{f}\right)\right)\right)\right)\right]} .
$$

Substituting (8) into (7) yields

$$
\begin{aligned}
f^{\prime}(0) & =w_{0} u^{\prime}\left(w_{0}\left(1+r_{f}\right)\right)\left(-\frac{E\left[\left(R_{g}-R\right)\left(1+k g^{\prime}\left(u\left(w^{\max }\right)-u\left(w_{0}\left(1+r_{f}\right)\right)\right)\right)\right]}{\left(1+r_{f}\right) E\left[\left(1+k g^{\prime}\left(u\left(w^{\max }\right)-u\left(w_{0}\left(1+r_{f}\right)\right)\right)\right)\right]}+E\left[R_{g}-R\right]\right) \\
& =-\frac{w_{0} u^{\prime}\left(w_{0}\left(1+r_{f}\right)\right) k}{E\left[1+k g^{\prime}\left(u\left(w^{\max }\right)-u\left(w_{0}\left(1+r_{f}\right)\right)\right)\right]} \cdot \operatorname{Cov}\left(R_{g}-R, g^{\prime}\left(u\left(w^{\max }\right)-u\left(w_{0}\left(1+r_{f}\right)\right)\right)\right) .
\end{aligned}
$$

We have

$$
\operatorname{Cov}\left(R_{g}-R, g^{\prime}\left(u\left(w^{\max }\right)-u\left(w_{0}\left(1+r_{f}\right)\right)\right)\right)=\operatorname{Cov}\left(R_{g}-R, g^{\prime}\left(u\left(w_{0}\left(1+\max \left(R, r_{f}\right)\right)\right)-u\left(w_{0}\left(1+r_{f}\right)\right)\right)\right)<0
$$

and thus $f^{\prime}(0)>0$. This implies $f(\bar{\alpha})>0$ for small $\bar{\alpha}$ as $f(0)=0$ and therefore $P_{k}\left(r_{g}, \bar{\alpha}\right)<P_{0}\left(r_{g}, \bar{\alpha}\right)$ for small $\bar{\alpha}$ and all $r_{g}$.

Next, we would like to show that $P_{k}\left(r_{g}, \bar{\alpha}\right)>P_{0}\left(r_{g}, \bar{\alpha}\right)$ for large $\bar{\alpha}$ and small $r_{g}$. This holds if and only if $f(\bar{\alpha})<0$ for large $\bar{\alpha}$ and small $r_{g}$ (see (6) for the definition of $f(\cdot)$ ). We have

$$
f(1)=E\left[u\left(\left(\left(w_{0}-P_{k}\left(r_{g}, 1\right)\right)\left(1+R_{g}\right)\right)\right]-E\left[u\left(w_{0}(1+R)\right)\right] .\right.
$$

At $r_{g}=-1,\left.f(1)\right|_{r_{g}=-1}=0$. Differentiating $f(1)$ with respect to $r_{g}$ implies

$$
\begin{aligned}
& \frac{\partial f(1)}{\partial r_{g}} \\
= & -\left.\frac{\partial P_{k}}{\partial r_{g}}\right|_{\bar{\alpha}=1} E\left[\left(1+R_{g}\right) u^{\prime}\left(\left(w_{0}-P_{k}\left(r_{g}, 1\right)\right)\left(1+R_{g}\right)\right)\right]+E\left[\frac{\partial R_{g}}{\partial r_{g}}\left(w_{0}-P_{k}\left(r_{g}, 1\right)\right) u^{\prime}\left(\left(w_{0}-P_{k}\left(r_{g}, 1\right)\right)\left(1+R_{g}\right)\right)\right] \\
= & -\left.\frac{\partial P_{k}}{\partial r_{g}}\right|_{\bar{\alpha}=1} E\left[\left(1+R_{g}\right) u^{\prime}\left(\left(w_{0}-P_{k}\left(r_{g}, 1\right)\right)\left(1+R_{g}\right)\right)\right]+\left(1+r_{g}\right)\left(w_{0}-P_{k}\left(r_{g}, 1\right)\right) u^{\prime}\left(\left(w_{0}-P_{k}\left(r_{g}, 1\right)\right)\left(1+r_{g}\right)\right)
\end{aligned}
$$

Evaluating at $r_{g}=-1$ yields

$$
\frac{\partial f(1)}{\partial r_{g}}=-\left.\frac{\partial P_{k}}{\partial r_{g}}\right|_{\bar{\alpha}=1, r_{g}=-1} E\left[(1+R) u^{\prime}\left(w_{0}(1+R)\right)\right] .
$$


Differentiating (1) with respect to $r_{g}$ implies

$$
\left[\begin{array}{c}
-\frac{\partial P_{k}}{\partial r_{g}} E\left[R\left(r_{g}, \bar{\alpha}\right) u^{\prime}\left(\left(w_{0}-P_{k}\right) R\left(r_{g}, \bar{\alpha}\right)\right)\left(1+k g^{\prime}\left(u\left(w^{\max }\right)-u\left(\left(w_{0}-P_{k}\right) R\left(r_{g}, \bar{\alpha}\right)\right)\right)\right)\right] \\
+E\left[\left(w_{0}-P_{k}\right) \frac{\partial R_{g}}{\partial r_{g}} u^{\prime}\left(\left(w_{0}-P_{k}\right) R\left(r_{g}, \bar{\alpha}\right)\right)\left(1+k g^{\prime}\left(u\left(w^{\max }\right)-u\left(\left(w_{0}-P_{k}\right) R\left(r_{g}, \bar{\alpha}\right)\right)\right)\right)\right]
\end{array}\right]=0
$$

where $P_{k}=P_{k}\left(r_{g}, \bar{\alpha}\right)$. For $\bar{\alpha}=1$ we get

$$
\left[\begin{array}{c}
-\left.\frac{\partial P_{k}}{\partial r_{g}}\right|_{\bar{\alpha}=1} E\left[\left(1+R_{g}\right) u^{\prime}\left(\left(w_{0}-P_{k}\left(r_{g}, 1\right)\right)\left(1+R_{g}\right)\right)\left(1+k g^{\prime}\left(u\left(w^{\max }\right)-u\left(\left(w_{0}-P_{k}\left(r_{g}, 1\right)\right)\left(1+R_{g}\right)\right)\right)\right)\right] \\
+\left(1+r_{g}\right)\left(w_{0}-P_{k}\right) u^{\prime}\left(\left(w_{0}-P_{k}\right)\left(1+r_{g}\right)\right)\left(1+k g^{\prime}\left(u\left(w_{0}\left(1+r_{f}\right)\right)-u\left(\left(w_{0}-P_{k}\right)\left(1+r_{g}\right)\right)\right)\right)
\end{array}\right]=0
$$

Evaluated at $r_{g}=-1$ implies $\left.\frac{\partial P_{k}}{\partial r_{g}}\right|_{\bar{\alpha}=1, r_{g}=-1}=0$ and thus $\left.\frac{\partial f(1)}{\partial r_{g}}\right|_{r_{g}=-1}=0$. Differentiating again implies

$$
\frac{\partial^{2} f(1)}{\partial r_{g}^{2}}=\left[\begin{array}{c}
-\left.\frac{\partial^{2} P_{k}}{\partial r_{g}^{2}}\right|_{\bar{\alpha}=1} E\left[\left(1+R_{g}\right) u^{\prime}\left(\left(w_{0}-P_{k}\left(r_{g}, 1\right)\right)\left(1+R_{g}\right)\right)\right] \\
-\left.\frac{\partial P_{k}}{\partial r_{g}}\right|_{\bar{\alpha}=1} E\left[\frac{\partial R_{g}}{\partial r_{g}} u^{\prime}\left(\left(w_{0}-P_{k}\left(r_{g}, 1\right)\right)\left(1+R_{g}\right)\right)\right] \\
+\left(\left.\frac{\partial P_{k}}{\partial r_{g}}\right|_{\bar{\alpha}=1}\right)^{2} E\left[\left(1+R_{g}\right)^{2} u^{\prime \prime}\left(\left(w_{0}-P_{k}\left(r_{g}, 1\right)\right)\left(1+R_{g}\right)\right)\right] \\
-\left.\frac{\partial P_{k}}{\partial r_{g}}\right|_{\bar{\alpha}=1}\left(w_{0}-P_{k}\left(r_{g}, 1\right)\right) E\left[\left(1+R_{g}\right) \frac{\partial R_{g}}{\partial r_{g}} u^{\prime \prime}\left(\left(w_{0}-P_{k}\left(r_{g}, 1\right)\right)\left(1+R_{g}\right)\right)\right] \\
+\left(w_{0}-P_{k}\left(r_{g}, 1\right)\right) u^{\prime}\left(\left(w_{0}-P_{k}\left(r_{g}, 1\right)\right)\left(1+r_{g}\right)\right) \\
-\left.\left(1+r_{g}\right) \frac{\partial P_{k}}{\partial r_{g}}\right|_{\bar{\alpha}=1} u^{\prime}\left(\left(w_{0}-P_{k}\left(r_{g}, 1\right)\right)\left(1+r_{g}\right)\right) \\
-\left.\left(1+r_{g}\right)^{2}\left(w_{0}-P_{k}\left(r_{g}, 1\right)\right) \frac{\partial P_{k}}{\partial r_{g}}\right|_{\bar{\alpha}=1} u^{\prime \prime}\left(\left(w_{0}-P_{k}\left(r_{g}, 1\right)\right)\left(1+r_{g}\right)\right)
\end{array}\right]
$$

At $r_{g}=-1$ we have $\left.\frac{\partial P_{k}}{\partial r_{g}}\right|_{\bar{\alpha}=1}=0$ and thus

$$
\left.\frac{\partial^{2} f(1)}{\partial r_{g}^{2}}\right|_{r_{g}=-1}=-\left.\frac{\partial^{2} P_{k}}{\partial r_{g}^{2}}\right|_{\bar{\alpha}=1} E\left[(1+R) u^{\prime}\left(w_{0}(1+R)\right)\right]+w_{0} u^{\prime}(0) .
$$

Differentiating (9) again with respect to $r_{g}$ and evaluating at $\bar{\alpha}=1$ and $r_{g}=-1$ implies

$$
\left[\begin{array}{c}
-\left.\frac{\partial^{2} P_{k}}{\partial r_{g}^{2}}\right|_{r_{g}=-1} E\left[(1+R) u^{\prime}\left(w_{0}(1+R)\right)\left(1+k g^{\prime}\left(u\left(w^{\max }\right)-u\left(w_{0}(1+R)\right)\right)\right)\right] \\
+w_{0} u^{\prime}(0)\left(1+k g^{\prime}\left(u\left(w_{0}\left(1+r_{f}\right)\right)-u(0)\right)\right)
\end{array}\right]=0
$$

and hence

$$
\left.\frac{\partial^{2} P_{k}}{\partial r_{g}^{2}}\right|_{r_{g}=-1}=\frac{w_{0} u^{\prime}(0)\left(1+k g^{\prime}\left(u\left(w_{0}\left(1+r_{f}\right)\right)-u(0)\right)\right)}{E\left[(1+R) u^{\prime}\left(w_{0}(1+R)\right)\left(1+k g^{\prime}\left(u\left(w^{\max }\right)-u\left(w_{0}(1+R)\right)\right)\right)\right]}
$$

Therefore

$$
\begin{aligned}
& \left.\frac{\partial^{2} f(1)}{\partial r_{g}^{2}}\right|_{r_{g}=-1} \\
= & -\frac{w_{0} u^{\prime}(0)\left(1+k g^{\prime}\left(u\left(w_{0}\left(1+r_{f}\right)\right)-u(0)\right)\right)}{E\left[(1+R) u^{\prime}\left(w_{0}(1+R)\right)\left(1+k g^{\prime}\left(u\left(w^{\max }\right)-u\left(w_{0}(1+R)\right)\right)\right)\right]} E\left[(1+R) u^{\prime}\left(w_{0}(1+R)\right)\right]+w_{0} u^{\prime}(0) \\
= & \frac{k w_{0} u^{\prime}(0) E\left[(1+R) u^{\prime}\left(w_{0}(1+R)\right)\left(g^{\prime}\left(u\left(w^{\max }\right)-u\left(w_{0}(1+R)\right)\right)-g^{\prime}\left(u\left(w_{0}\left(1+r_{f}\right)\right)-u(0)\right)\right)\right]}{E\left[(1+R) u^{\prime}\left(w_{0}(1+R)\right)\left(1+k g^{\prime}\left(u\left(w^{\max }\right)-u\left(w_{0}(1+R)\right)\right)\right)\right]}
\end{aligned}
$$

For $R<r_{f}$ we have 


$$
\begin{aligned}
& g^{\prime}\left(u\left(w^{\max }\right)-u\left(w_{0}(1+R)\right)\right)-g^{\prime}\left(u\left(w_{0}\left(1+r_{f}\right)\right)-u(0)\right) \\
= & g^{\prime}\left(u\left(w_{0}\left(1+r_{f}\right)\right)-u\left(w_{0}(1+R)\right)\right)-g^{\prime}\left(u\left(w_{0}\left(1+r_{f}\right)\right)-u(0)\right)<0
\end{aligned}
$$

For $R>r_{f}$ we have

$$
\begin{aligned}
& g^{\prime}\left(u\left(w^{\max }\right)-u\left(w_{0}(1+R)\right)\right)-g^{\prime}\left(u\left(w_{0}\left(1+r_{f}\right)\right)-u(0)\right) \\
= & g^{\prime}(0)-g^{\prime}\left(u\left(w_{0}\left(1+r_{f}\right)\right)-u(0)\right)<0
\end{aligned}
$$

Therefore $\left.\frac{\partial^{2} f(1)}{\partial r_{g}^{2}}\right|_{r_{g}=-1}<0$. As $\left.f(1)\right|_{r_{g}=-1}=0$ and $\left.\frac{\partial f(1)}{\partial r_{g}}\right|_{r_{g}=-1}=0$ we thus derived $f(1)<0$ for small guarantee levels, i.e. close to $r_{g}=-1$. This in turn yields $P_{k}\left(r_{g}, \bar{\alpha}\right)>P_{0}\left(r_{g}, \bar{\alpha}\right)$ for large $\bar{\alpha}$ and small $r_{g}$. 


\section{References}

[1] Agnew, J., P. Balduzzi, and A. Sunden, 2003. Portfolio choice and trading in a large 401k plan. American Economic Review 93 (1), 193-215.

[2] Ameriks, J. and S. Zeldes, 2000. How do household portfolio shares vary with age?. TIAA-CREF Working Paper.

[3] Baron, J. and J. Hershey, 1988. Outcome bias in decision evaluation. Journal of Personality and Social Psychology 54 (4), 569-579.

[4] Bell, D. E., 1982. Regret in decision making under uncertainty. Operations Research 30 (5), 961-981.

[5] Bodie, Z. and R. Merton, 1993. Pension Benefit Guarantees in the United States: A Functional Analysis. In: The Future of Pensions in the United States. R. Schmitt, ed. University of Pennsylvania Press, Philadelphia, pp. 194-234.

[6] Boulier, J. F., S. J. Huang, and G. Taillard, 2001. Optimal management under stochastic interest rates: the case of a protected defined contribution pension fund. Insurance: Mathematics and Economics 28 (2), 173-189.

[7] Braun, M. and A. Muermann, 2004. The impact of regret on the demand for insurance. Journal of Risk and Insurance 71 (4), 737-767.

[8] Cogan, J. F. and O. S. Mitchell, 2003. Perspectives from the president's commission on social security reform. Journal of Economic Perspectives 17 (2), 149-172.

[9] Connolly, T. and J. Reb, 2003. Omission bias in vaccination decisions: where's the "omission"? where's the "bias"? Organizational Behavior and Human Decision Processes 91 (2), 186-202.

[10] Deelstra, G., M. Grasselli, and P. F. Koehl, 2003. Optimal investment strategies in the presence of a minimum guarantee. Insurance: Mathematics and Economics 33 (1), 189-207.

[11] Feldstein, Martin S. and Andrew A. Samwick, 2001. Potential paths of social security reform. NBER Working Paper W8592.

[12] Fischer, K. P., 1999. Pricing pension fund guarantees: a discrete martingale approach. Canadian Journal of Administrative Sciences 16 (3), 256-266.

[13] Gollier, Ch., and B. Salanie, 2005. Individual decisions under risk, risk-sharing and asset prices with regret. Working paper.

[14] van der Hoek, J. and M. Sherris, 2001. A class of non-expected utility risk measures and implications for asset allocations. Insurance: Mathematics and Economics 28 (1), 69-82.

[15] Lachance, M.-E., O. S. Mitchell, and K. Smetters, 2003. Guaranteeing defined contribution pensions: the option to buy back a defined benefit promise. Journal of Risk and Insurance 70 (1), 1-16.

[16] Lachance, M.-E. and O. S. Mitchell, 2003. Understanding Individual Account Guarantees. In: The Pension Challenge: Risk Transfers and Retirement Income Security. Olivia S. Mitchell and Kent Smetters, eds. Pension Research Council, Oxford University Press, Oxford, pp. 159-186.

[17] Loomes, G., 1988. Further evidence of the impact of regret and disappointment in choice under uncertainty. Econometrica 55 (217), 47-62.

[18] Loomes, G., C. Starmer, and R. Sugden, 1992. Are preferences monotonic - testing some predictions of regret theory. Econometrica 59 (233), 17-33.

[19] Loomes, G., and R. Sugden, 1982. Regret theory: an alternative theory of rational choice under uncertainty. Economic Journal 92 (368), 805-824. 
[20] Loomes, G., and R. Sugden, 1987. Testing for regret and disappointment in choice under uncertainty. Economic Journal 97 (Suppl.), 118-129.

[21] Madrian, B. C. and D. F. Shea, 2001. The power of suggestion: inertia in 401(k) participation and savings behavior. The Quarterly Journal of Economics 116 (4), 1149-1187.

[22] Maurer, R. and Ch. Schlag, 2003. Money-Back Guarantees in Individual Account Pensions: Evidence from the German Pension Reform. In: The Pension Challenge: Risk Transfers and Retirement Income Security. Olivia S. Mitchell and Kent Smetters, eds. Pension Research Council, Oxford University Press, Oxford, pp. 187-213.

[23] Mitchell, O. S. and K. Smetters, eds., 2003. The Pension Challenge: Risk Management and Retirement Income Security. Pension Research Council, The Wharton School, Philadelphia, pp. 1-18.

[24] Mitchell, O. S. and S. P. Utkus, eds., 2004. Pension Design and Structure: New Lessons from Behavioral Finance. Oxford University Press, Oxford.

[25] Pennachi, G. G., 1999. The value of guarantees on pension fund conversion. Journal of Risk and Insurance 66 (2), 219-237.

[26] Quiggin, J., 1994. Regret theory with general choice sets. Journal of Risk and Uncertainty 8 (2), 153-165.

[27] Smetters, K., 2002. Controlling the costs of minimum benefit guarantees in public pension conversions. Journal of Pension Economics and Finance 1 (1), 9-34.

[28] Starmer, C., and R. Sugden, 1993. Testing for juxtaposition and event-splitting effects. Journal of Risk and Uncertainty 6 (3), 235-254.

[29] Sugden, R., 1993. An axiomatic foundation of regret. Journal of Economic Theory 60 (1), 159-180.

[30] Turner, J. and D. Rajnes, 2003. Retirement Guarantees in Voluntary Defined Contribution Plans. In: The Pension Challenge: Risk Transfers and Retirement Income Security. Olivia S. Mitchell and Kent Smetters, eds. Pension Research Council, Oxford University Press, Oxford, pp. 251-267.

[31] Walliser, J., 2003. Retirement Guarantees in Mandatory Defined Contribution Systems. In: The Pension Challenge: Risk Transfers and Retirement Income Security. Olivia S. Mitchell and Kent Smetters, eds. Pension Research Council, Oxford University Press, Oxford, pp. 238-250. 